www.jmscr.igmpublication.org

Impact Factor 5.84

Index Copernicus Value: 83.27

ISSN (e)-2347-176x ISSN (p) 2455-0450

crossref DOI: _https://dx.doi.org/10.18535/jmscr/v5i7.170

Journal Of Medical Science And Clinical Research

IGM Publication

An Official Publication of IGM Publication

\title{
Laparoscopic Splenectomy in Patients with Haematological Disorders: A Prospective Study
}

\author{
Authors \\ Dr Nitin Dnyaneshwar Sherkar ${ }^{1}$, Dr Nilesh Nagdeve ${ }^{2}$, Dr Nilesh Mangam ${ }^{3}$ \\ ${ }^{1,3}$ Assistant Professor, ${ }^{2}$ Associate Professor \\ Department of General Surgery, Government Medical College, Nagpur (MS) India \\ Corresponding Author:
}

Dr Nilesh Nagdeve

Associate Professor, Department of General Surgery, Government Medical College, Nagpur (MS) India

\begin{abstract}
Introduction: Laparoscopic splenectomy (LS) was first described by Delaitre in 1992. Since then it has become a popular treatment for benign diseases. It is considered preferred surgical procedure in cases where spleen size is normal. Its use in cases with hematological disorders like thalassemia, sickle cell disease and idiopathic thrombocytopenic purpura has not been extensively studied. In our region where haemoglobinopathies are prevalent in tribals and some communities like kachis, Sindhis and lohanas the eventuality that a patient will require splenectomy is fairly common. These patients (Specially patients with Beta thalassemia major) usually have grossly enlarged spleen which becomes a site for RBC sequestration and consequently there is increase frequency for transfusion required to maintain hemoglobin at a normal level. The utility of $L S$ in these patients had been controversial and in fact grossly enlarged spleen has been considered a contraindication to LS by many authors. With increased experience of surgeons and improvements in laparoscopic technique more and more patients with haemoglobinopathies are being operated with laparoscopic techniques. We conducted this prospective study to know role of $L S$ in patients with various hematological disorders.

Aims And Objectives: To study the indications, feasibility, safety, technical difficulties, intraoperative complications, postoperative course and outcome following elective laparoscopic splenectomy in patients with hematological disorders.

Methods and Methods: This was a prospective study conducted at a tertiary care hospital of an urban area. The study was approved by institutional ethical committee. In Our institute 32 patients underwent laparoscopic splenectomy over a period of 2 years. The records of 32 patients were evaluated for age, gender, length of hospital stay, time to resume normal diet, conversion rate, operation time and post-operative course. All patients were operated in same institute. The indication for splenectomy included hypersplenism, increased frequency of transfusion, abdominal pain, respiratory difficulty due to gross abdominal distension and sever thrombocytopenia not responding to steroids or IvIg. The data was analysed using paired t test and a $P$ value of $<0.05$ was considered significant.

Results: Majority of the patients were in the age group $6-10$ years (50.625\%), followed by $11-15$ years $(31.25 \%), 20$ patients were male (62.5\%) and 12 were female (37.5\%). Most common indication for splenectomy was SCD in 14 patients $(43.75 \%)$. The mean duration of surgery was $127.81(+30.07)$ mins. The mean operative blood loss was 46.56(+30.09) $\mathrm{ml}$, 4 cases were converted to open surgery due to bleeding from splenic hilum. Most common postoperative complications occurred was prolonged ileus in 10 patients $(31.25 \%)$. In most of the patients oral feeds were started within 24 hours (22 patients (68.75\%). The mean duration of analgesia required was $5.28(+1.83)$ days. The mean post-operative hospital stay was $6.37( \pm 1.47)$ days. Follow up blood counts were normal in all patients and no patients had any complication in postoperative period.

Conclusion: Though Laparoscopic Splenectomy is widely accepted to be standard procedure in benign diseases its role
\end{abstract}


in haematological disorders remained controversial. Many surgeons are still reluctant to do LS in patients with enlarged spleen due to high conversion rates to open procedure. With increased expertise and improved technique LS can be safely done. Our study confirms that though there is a steep learning curve involved, with time and growing operator experience it is possible to extend the benefits of the laparoscopic approach to a wider spectrum of these patients including patients having splenomegaly secondary to various haemoglobinopathies.

Keywords: Laparoscopic Splenectomy, Haemoglobinopathies, Haematological disorders, Outcome.

\section{Introduction}

A significant proportion of Indian population carries the traits for various hematological disorders. Haemoglobinopathies particularly thalassaemias, sickle cell disease and $\mathrm{HbS}$ are a common occurrence in various predisposed communities (Tribals, Sindhis and kachis etc) ${ }^{[1]}$. These haemoglobinopathies are more prevalent in north eastern states, West Bengal, Odisha and Andaman Nicobar islands. In Maharashtra Haemoglobinopathies like sickle cell disease is widespread in all the eastern districts including Vidharbha, saputara and tribal regions of Marathwada [2]. The tribal groups like Bhils, Madias, Pawaras, Pardhans and Otkars are found to have a very high prevalence rate of $\mathrm{Hb} \mathrm{S}$ (20$35 \%$ ). It has been found that Gadchiroli, Chandrapur, Nagpur, Bhandara, Yoetmal and Nandurbar districts would have more than 5000 cases of sickle cell anemia ${ }^{[3]}$. All these patients, particularly those with thalassemia major are at risk of developing splenomegaly and its consequences. In patients with thalassemia hypersplenism is responsible for increased blood transfusion requirement, thrombocytopenia and iron overload ${ }^{[4]}$. Majority of such patients are eventually advised splenectomy. Other indications for splenectomy in hematological disorders include idiopathic thrombocytopenic purpura, hereditary spherocytosis and autoimmune hemolytic anemia $^{[5]}$.

In 1992 laparoscopic splenectomy was first described by Delaitre ${ }^{[6]}$. Since then laparoscopic splenectomy has been a preferred surgical procedure for being diseases having normal sized spleen ${ }^{[7]}$. This technique was usually avoided in patients with moderate to severe splenomegaly due to expected difficulties during intra-operative manipulation while doing laparoscopic splenectomy ${ }^{[8]}$. Moreover high conversion rates to open procedure were also reported making LS a contraindication in patients with significant splenomegaly ${ }^{[9]}$. However with time there is improment

in laparoscopic techniques and with experience many surgeons are reporting less conversion rates even in patients with moderate splenomegaly ${ }^{[10]}$. With this background we conducted this prospective study to know role of LS in patients with various hematological disorders.

\section{Materials and Methods}

This was a prospective study comprising of 32 patients having haematological disorders in whom laparoscopic splenectomy was done. Hospital ethical committee approved the study.

Patients undergoing laparoscopic splenectomy for various haematological disorders like thalassemia, ITP, sickle cell disease and hereditary spherocytosis were included in this study.

\section{Inclusion criteria}

- Patients with haematological disorders undergoing laparoscopic splenectomy.

\section{Exclusion criteria}

- Patients who refused consent to be part of study.

- Patients having cirrhosis with portal hypertension and splenomegaly.

- Patients with coagulopathies, immunocompromised individuals and patients with trauma.

The data collected from these patients included demographic, clinical history, physical findings, detailed investigations, operative details and postoperative findings. All patients were given a polyvalent vaccine against pneumococcal (active against 23 serotypes) and meningococcal infection two weeks prior to surgery as prophylaxis. Single 
0.5-mL dose was administered intramuscularly or subcutaneously. Patients were admitted after 15 days for elective laparoscopic splenectomy.

All patients underwent a thorough clinical examination. Blood investigations included complete blood count, peripheral blood smear, liver function test, renal function test, serum electrolytes, blood sugar level, coagulation profile, blood grouping and typing, HIV and HBsAg. ECG, Xray chest PA view and 2-D Echo was done in patients as advised by anaesthetist. Laparoscopic splenectomy was done according to the standard protocol. Post-operatively patients were managed in accordance with the hospital protocols. Various indications, procedure, complications and outcome were studied in detail.

\section{Results}

Most of the patients were in the age group $6-10$ years $(50 \%)$, followed by $11-15$ years $(31.25 \%)$ and more than 15 years $(18.75 \%)$ mean age of patients was $13.92(+10.56)$ years.

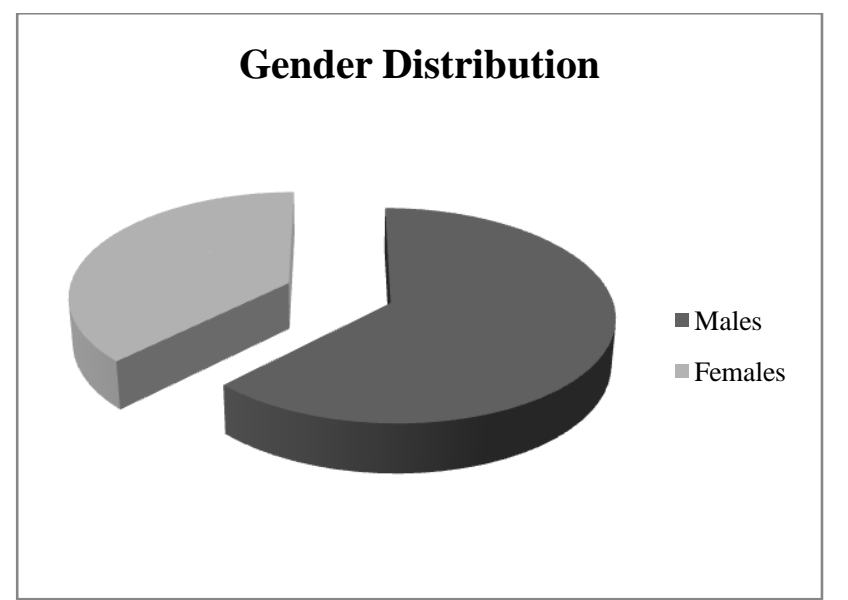

Figure 1 Gender Distribution of the Studied Cases.

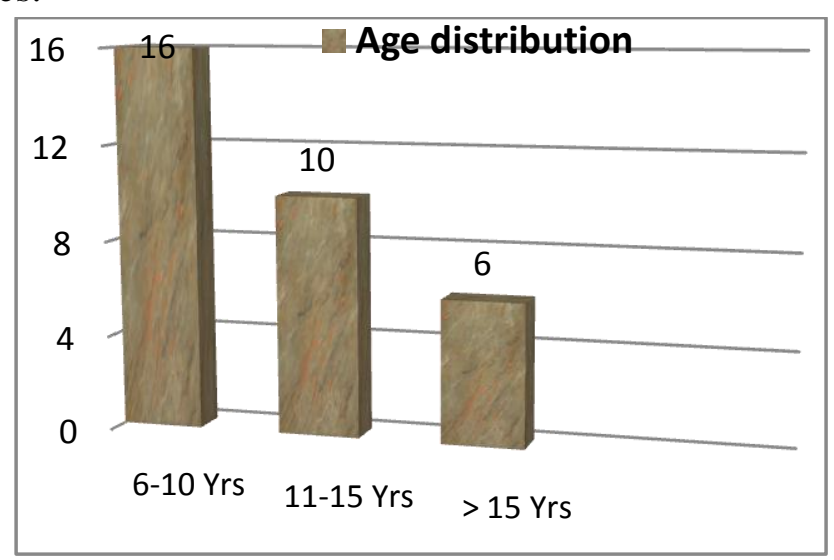

Figure 2 : Age Distribution of the studied cases. Since the purpose of the study was to evaluate the feasibility of laparoscopic splenectomy in patients having hematological disorders only patients with diagnosed with hematological disorders were included in this study. The most common indication for splenectomy amongst these patients was found to be sickle cell disease (14/32) followed by thalassemia (9/32), idiopathic thrombocytopenic purpura (4/32) and hereditary spherocytosis (4/32). 1 patient with splenic cyst was also included in this study because the patient also had coexistent autoimmune hemolytic anemia.

Table 1 : Indications of splenectomy in studied cases

\begin{tabular}{lcc}
\hline Diagnosis & No. of cases & Percentage \\
\hline Sickle cell disease & 14 & $43.75 \%$ \\
Thalassemia & 09 & $28.12 \%$ \\
ITP & 04 & $12.5 \%$ \\
Hereditary spherocytosis & 04 & $12.5 \%$ \\
Splenic cyst & 01 & $3.12 \%$ \\
Total & 32 & $100 \%$ \\
\hline
\end{tabular}

We started the procedure with three ports, $10-\mathrm{mm}$ umbilical, 5-mm high epigastric and 10-mm between the umbilicus and xiphisternum and whenever necessary placed fourth 5-mm port about 1 inch above the anterior superior iliac spine in the left mid-clavicular line.

Table 2 : Number of ports used in studied cases

\begin{tabular}{l|cc}
\hline No. of Ports used & No. of patients & Percentage \\
\hline 3 Ports & 9 & $28.12 \%$ \\
4 Ports & 23 & $71.87 \%$ \\
Total & 32 & $100 \%$ \\
\hline
\end{tabular}

To know the impact of experience on operative duration, we divided the total study period three groups: Group 1- first 10 patients, Group 2- next 10 patients and Group 3-last 12 patients. The difference was found to be statistically highly significant with a $\mathrm{p}$ value $<0.0001$. This difference in the mean duration of surgery was mainly due to the learning curve for the laparoscopic splenectomy.

Table 3 : Effect of experience of surgerons on Mean duration of the surgery. 


\section{JMSCR VoI||05||Issue ||07||Page 25342-25347||July}

\begin{tabular}{llc}
\hline Groups & $\begin{array}{l}\text { No. of pa- } \\
\text { tients }\end{array}$ & $\begin{array}{c}\text { Mean duration of sur- } \\
\text { gery in mins (mean } \pm \\
\text { SD) }\end{array}$ \\
\hline Group 1 & First 10 & $154 \pm 28.65$ \\
Group 2 & Next 10 & $128 \pm 25.40$ \\
Group 3 & Last 12 & $105.83 \pm 14.11$ \\
$\begin{array}{l}\text { Spearman's corre- } \\
\text { lation(Rho) } \\
\text { p- value }\end{array}$ & -0.7052 & \\
\hline
\end{tabular}

The intra-operative blood loss was $<50 \mathrm{ml}$ in 28 patients (87.5\%), $51-100 \mathrm{ml}$ in 2 patients $(6.25 \%)$ and $101-150 \mathrm{ml}$ in remaining 2 patients $(6.25 \%)$. And the mean operative blood loss was 46.56( \pm 30.09$) \mathrm{ml}$ (range $25-150 \mathrm{ml}$ ).

Table 4 : Blood loss during laparoscopic splenectomy.

\begin{tabular}{|lcc|}
$\begin{array}{l}\text { Intraoperative } \\
\text { Blood Loss }\end{array}$ & No Of patients & Percentage \\
\hline$<\mathbf{5 0} \mathbf{~ m l}$ & 28 & 87.5 \\
\hline $\mathbf{5 1 - 1 0 0} \mathbf{~ m l}$ & 2 & $6.25 \%$ \\
\hline $\mathbf{1 0 1 - 1 5 0} \mathbf{~ m l}$ & 2 & $6.25 \%$ \\
\hline
\end{tabular}

4 cases were converted to open surgery due to bleeding from splenic hilum. The amount of blood loss during this procedure was $140 \mathrm{ml}$ in first case, $90 \mathrm{ml}$ in second case, $150 \mathrm{ml}$ in third case and $100 \mathrm{ml}$ in last case. All these conversions occurred in first 16 cases of the study. Bleeding from splenic hilum was the only complication occurred in this study in 4 cases which were converted to open surgery. Conversion rate was $12.5 \%$.specimen retrieval was done by morcellation in 10 patients $(31.25 \%)$ and by incision in 22 patients $(68.75 \%)$. Out of 22 patients, Pfannenstiel incision was used in 11 patients (34.37\%), midline incision joining ports in 8 patients $(25.00 \%)$ and upper abdominal transverse incision in 3 patients $(9.37 \%)$.

Table 5 : Method of splenic retrieval in studied cases.

\begin{tabular}{|c|c|c|}
\hline \multicolumn{2}{|c|}{ Specimen retrieval } & No of patients \\
\hline \multicolumn{2}{|c|}{ morcellation } & $10(31.25 \%)$ \\
\hline \multirow[t]{3}{*}{ Incision } & Pfannenstiel incision & $11(34.37 \%)$ \\
\hline & midline incision & $8 \quad(25.00 \%)$ \\
\hline & $\begin{array}{l}\text { upper abdominal } \\
\text { transverse incision }\end{array}$ & $3 \quad(9.37 \%)$ \\
\hline \multicolumn{2}{|l|}{ Total } & $32(100 \%)$ \\
\hline
\end{tabular}

Post-operative oral feeds were started after return of bowel sounds. In our study oral feeds were started within 24 hours in 22 patients $(68.75 \%)$, between $24-48$ hours in 6 patients $(18.75 \%)$, on $3^{\text {rd }}$ day in 3 patients $(9.37 \%)$ and after 3 days in 1 patient $(3.12 \%)$.

The duration of post-operative analgesia requirement in our study varied from $3-9$ days. The mean duration of analgesia required was 5.28 $( \pm 1.83)$ days. The post-operative complications occurred in our study were prolonged ileus in 10 patients $(31.25 \%)$, and pneumonia and overwhelming post-splenectomy infection occurred in 1 patient $(3.12 \%)$.

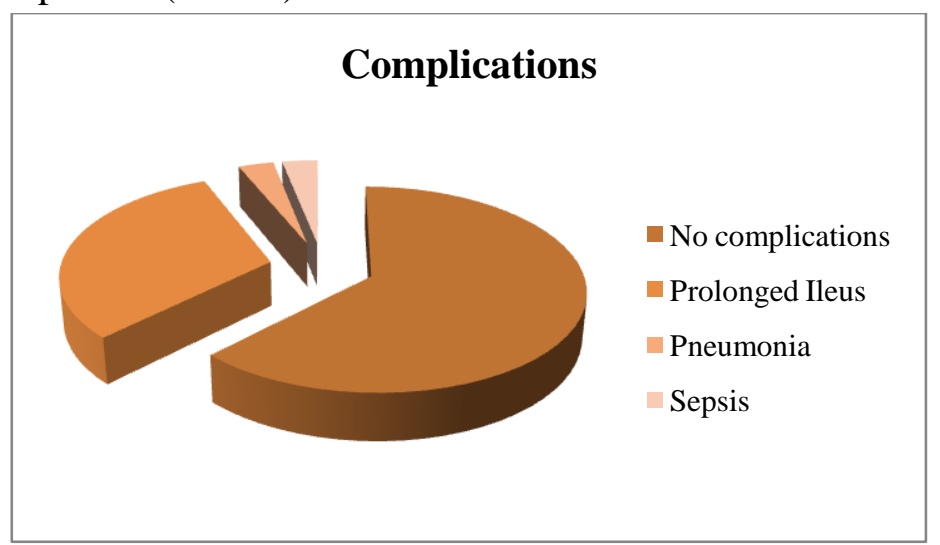

Figure 3 : Post-Operative complications in studied cases.

The post-operative hospital stay was $<5$ days in 3 patients $(9.37 \%), 5-7$ days in 23 patients $(71.87 \%)$ and $>7$ days in 6 patients $(18.75 \%)$. The mean post-operative hospital stay study was $6.37( \pm 1.47)$ (range 04-10 days). Patients were followed up in outpatient department at 1-month, 3-months and 6-months with blood counts, USG abdomen for splenic vein thrombosis. In our study, follow up blood counts were normal in all patients and no patients had any complication in postoperative period.

\section{Discussion}

Laparoscopic techniques have gained wide acceptance with growing surgical experience and technological development. Laparoscopic splenectomy is a procedure of high complexity, whose technical difficulty is directly related to the presence of adhesions to other organs and the relative size of the spleen ${ }^{[11]}$. Advances in surgical technique, operative conduct, and instrumentation 
have made it feasible to perform splenectomy laparoscopically with good outcomes and minimal morbidity in a variety of different pathologic conditions; obesity, malignancy, pregnancy, and splenomegaly ${ }^{[12]}$. Our area has more incidence of sickle cell disease and thalassemia which is reflected in the indications for splenectomy.

Size is an important denominator for success of splenectomy especially in pediatric age group. Bigger spleens are associated with perisplenic adhesions. Also, the splenic vein is grossly dilated in these patients with hilar varices. Bigger spleens are tricky to handle. Also, in these patients less splenic size to abdominal space ratio decreases the chances of removal by bagging and morcellation ${ }^{[13]}$. In our study, all patients who required conversion $(n=4)$, splenic size was more than $15 \mathrm{cms}$. Very massive splenomegaly $(\geq 25 \mathrm{~cm}$ craniocaudal length) remains a relative contraindication to a laparoscopic approach as the technical difficulties in exposure and manipulation of these organs becomes increasingly difficult, and the advantages of the laparoscopic approach becomes less clear because conversion to open, reoperation for bleeding, and other complications are more frequent [14].

According to Targarona EM et al preliminary evaluation of LS in patients with large spleens suggests that despite the longer operative time required, it is feasible and may potentially offer the same advantages (shorter stay and faster recovery) as it does to healthier patients with smaller spleens [15].

Bleeding from splenic hilum was the only complication occurred in our study in 4 cases which were converted to open surgery. No any other complications like pancreatic injury, bowel injury or diaphragmatic injury occurred during laparoscopic splenectomy. This was mainly due to the adoption of the right lateral approach instead of the supine approach, use of the ultrasonic activated scalpel instead of bipolar electrocautery for control of short gastric vessels and the dissection of ligaments and careful dissection during the procedure.
It is of interest to note that we have completed the laparoscopic splenectomy procedure using 3 ports in 9 cases.It appears that careful dissection, individual control of the splenic arterial and venous branches is the safest approach as evidenced by the lack of major intraoperative bleeding. We have not used vascular staples.

Laparoscopic splenectomy is technically demanding and requires the services of a surgeon well versed with advanced laparoscopic techniques. At the commencement of this study, we had completed 32 laparoscopic splenectomies at our institution.

Important changes were implemented and standards were established at the beginning of this study which marked the transition towards standardization of operative approach, for instance the adoption of the right lateral approach instead of the supine approach, use of the ultrasonic activated scalpel instead of bipolar electrocautery for control of short gastric vessels and the dissection of ligaments. This has shortened operative time and enabled quicker and reliable hilar vascular control.

\section{Conclusion}

Elective laparoscopic splenectomy is feasible and safe both in pediatric and adult patients. Benefits of laparoscopic splenectomy including early postoperative mobilization, early resumption of oral feeds, less duration of post-operative analgesics requirement and shorter hospital stay are also confirmed in this study. Though there is a steep learning curve involved, with time and growing operator experience it is possible to extend the benefits of the laparoscopic approach to a wider spectrum of these patients.

\section{Conflict of Interest: None}

\section{References}

1. Patel AG, Shah AP, Sorathiya SM, Gupte SC. Hemoglobinopathies in South Gujarat population and incidence of anemia in 
them. Indian Journal of Human Genetics. 2012;18(3):294-298.

2. Ghosh K, Colah RB, Mukherjee MB. Haemoglobinopathies in tribal populations of India. The Indian Journal of Medical Research. 2015;141(5):505-508.

3. Kate SL, Lingojwar DP. Epidemiology of sickle cell disorder in the state of Maharashtra. Indian J Hum Genet. 2002;3:1617.

4. Taher A, Tyan PI. THE SPLEEN. In: Cappellini MD, Cohen A, Porter J, et al., editors. Guidelines for the Management of Transfusion Dependent Thalassaemia (TDT) [Internet]. 3rd edition. Nicosia (CY): Thalassaemia International Federation; 2014.

5. Russell SJ, Richards JD. Medical indications for splenectomy. $\mathrm{Br} \mathrm{J}$ Hosp Med.1989 Aug;42(2):120-3, 125-6, 127.

6. Delaitre B, Maignien B. (1991) Splenectomy by the laparoscopic approach. Report of a case. Presse Med 20:2263.

7. Karadag CA, Erginel B, Kuzdan O, et al. Impact of Spleen Size on Outcomes in Laparoscopic Splenectomy in Children. Gastroenterology Research and Practice. 2015;2015:603915.

8. Su C-H, Yin T-C, Huang C-J, Fan W-C, Hsieh J-S. Laparoscopic splenectomy for splenomegaly using a homemade retrieval BAG. Videosurgery and other Miniinvasive Techniques. 2013;8(4):327333.

9. Grahn SW, Alvarez J 3rd, Kirkwood K. Trends in laparoscopic splenectomy for massive splenomegaly. Arch Surg. 2006 Aug;141(8):755-61; discussion 761-2.

10. Hassan ME, Al Ali K. Massive Splenomegaly in Children: Laparoscopic Versus Open Splenectomy. JSLS : Journal of the Society of Laparoendoscopic Surgeons. 2014;18(3):e2014.00245.
11. Tan M, Zheng C-X, Wu Z-M, Chen G-T, Chen L-H, Zhao Z-X. Laparoscopic splenectomy: the latest technical evaluation. World Journal of Gastroenterology: WJG. 2003;9(5):1086-1089.

12. Dominguez EP, Choi YU, Scott BG, Yahanda AM, Graviss EA, Sweeney JF. Impact of morbid obesity on outcome of laparoscopic splenectomy. Surg Endosc. 2007 Mar;21(3):422-6. Epub 2006 Nov

13. Hashizume M, Migo S, Tsugawa K, Tanoue K, Ohta M, Sugimachi K. Laparoscopicsplenectomy with the newly devised morcellator. Hepatogastroenterology. 1998MarApr;45(20):554-7. PubMed PMID: 9638450.

14. Feldman LS; Laparoscopic Splenectomy: Standardized Approach. World J Surg (2011) 35:1487-1495

15. Targarona EM, Espert JJ, Balagu6 C, et al. Splenomegaly Should Not Be Considered a Contraindication for Laparoscopic Splenectomy. Annals Of Surgery Vol. 228, No. 1, 35-39. 